\title{
Wag31, a homologue of the cell division protein DivIVA, regulates growth, morphology and polar cell wall synthesis in mycobacteria

\begin{abstract}
Correspondence
\end{abstract} \\ Choong-Min Kang cmkang@wayne.edu \\ Received 15 October 2007 \\ Revised 30 November 2007 \\ Accepted 5 December 2007 \\ Choong-Min Kang, ${ }^{1}$ Seeta Nyayapathy, ${ }^{1}$ Jung-Yeon Lee, ${ }^{2}$ Joo-Won Suh ${ }^{2}$ and Robert N. Husson ${ }^{3}$

\author{
${ }^{1}$ Department of Biological Science, Wayne State University, 5047 Gullen Mall, Detroit, MI 48202, \\ USA \\ ${ }^{2}$ Department of Biological Science, Myongji University, San 38-2, Namdong, Yongin, \\ ${ }^{3}$ Division of Infectious Diseases, Children's Hospital Boston, Harvard Medical School, \\ 300 Longwood Ave., Boston, MA 02115, USA
} Republic of Korea

\begin{abstract}
The Mycobacterium tuberculosis genome contains 11 serine/threonine kinase genes, and the products of two of these, $\mathrm{PknA}$ and $\mathrm{PknB}$, are key components of a signal transduction pathway these kinases is Wag31, a homologue of the cell division protein DivIVA that is present, but not known to be phosphorylated, in other Gram-positive bacteria. Here, we investigate the localization and function of Wag31 and its phosphorylation. We demonstrate that Wag31 is localized to the cell poles. We further show that wag31 is an essential gene and that depletion of its product causes a dramatic morphological change in which one end of the cell becomes round rather than rod-shaped. This abnormal morphology appears to be caused by a defect in polar peptidoglycan synthesis. Finally, expression of M. tuberculosis wag31 in the wag31 conditional mutant of Mycobacterium smegmatis altered the growth rate in a manner that depended on the phospho-acceptor residue encoded by the allele being expressed. Taken together, these results indicate that Wag31 regulates cell shape and cell wall synthesis in $M$. tuberculosis through a molecular mechanism by which the activity of Wag31 can be modulated in response to environmental signals.
\end{abstract} that regulates cell division and/or morphology. Previously, we have shown that one substrate of
}

\section{INTRODUCTION}

Tuberculosis is a major and increasing health problem worldwide, not only because of current cases of active disease, which have a high mortality, but also because of the threat of latency (World Health Organization, 2007). The problem of latency, resulting in an enormous reservoir of infected individuals worldwide with the potential to develop active tuberculosis, is a major obstacle to tuberculosis control. It is not clear, however, how $M$. tuberculosis achieves or maintains a latent state in vivo. A key aspect of latency may be the ability of M. tuberculosis to regulate cell division in response to specific host signals in

Abbreviations: DIC, differential interference contrast; Van-Alexa568, vancomycin-Alexa568 conjugate; Van-FL, vancomycin-fluorescein conjugate.

Two supplementary figures, showing the position of wag31 in the $d c w$ cluster in $M$. tuberculosis and $M$. smegmatis and the strategies for disruption of $M$. smegmatis wag31 and confirmation of the wag31 conditional mutant by $\mathrm{PCR}$, and a supplementary table listing the primers used in this research, are available with the online version of this paper. making the transition between active replication and nonreplicating persistence (Flynn \& Ernst, 2000; Wayne \& Hayes, 1996).

To alternate between the active and latent states, $M$. tuberculosis must be able to sense and respond to signals in the host environment. In both eukaryotic and prokaryotic cells, reversible protein phosphorylation is the most common mechanism by which environmental signals are transmitted to regulate gene expression. In bacteria, twocomponent systems transmit signals by phospho-transfer from a histidine residue on a sensor protein to an aspartyl residue on a response regulator protein (Magasanik, 1995). Many prokaryotes also possess eukaryotic-like protein kinases that function via reversible phosphorylation of serine, threonine or tyrosine residues; of these, the most widely distributed are serine/threonine protein kinases (STPKs) (Leonard et al., 1998). M. tuberculosis has genes encoding 11 STPKs (Av-Gay \& Everett, 2000). All but two of these kinases have predicted transmembrane domains with the kinase domain located intracellularly, suggesting 
that these STPKs play an important role in signal transduction in M. tuberculosis.

The kinase genes $p k n A$ and $p k n B$ are located near the origin of replication in an operon with genes predicted to function in cell wall synthesis and morphology. This operon contains a phosphatase gene ( $p s t P)$ and two genes that are highly homologous to $\operatorname{rod} A$ and $p b p A$, which in both Gram-positive and Gram-negative bacteria have been shown to play a major role in cell wall synthesis and cell morphology (Henriques et al., 1998; Rodriguez \& de Pedro, 1990; Thibessard et al., 2002). In our previous study, we have shown that $p k n A$ and $p k n B$ are primarily expressed during exponential growth, and that overexpression of these kinases impairs growth and alters cell morphology, suggesting that these kinases play an important role in a signal transduction pathway that regulates cell division/morphology in $M$. tuberculosis. Using peptide library screening and proteomics, we also identified three in vivo substrates of PnkA and PnkB. One substrate is PknB itself, the product of autophosphorylation. The others are Rv1422, a conserved hypothetical protein of unknown function, and Wag31, a homologue of DivIVA, a protein present during the early stages of cell division in Grampositive bacteria. While Wag31 is highly phosphorylated by overexpression of either $p k n A$ or $p k n B$ in $M$. tuberculosis, only PknA can phosphorylate Wag31 in vitro, suggesting that PknA phosphorylates Wag31 directly and that PknB does so indirectly through PknA (Kang et al., 2005).

In this work we focus on the function of Wag31. This protein was originally identified as an antigen of pathogenic mycobacteria that was recognized by serum from persons with leprosy and tuberculosis (Hermans et al., 1995). Sequence analysis showed that Wag31 is a homologue of the Gram-positive cell division protein DivIVA (Cole et al., 1998; Flardh, 2003). Although DivIVA is believed to function in cell division in all Gram-positive bacteria, the specific roles that it plays appear to vary in a species-specific manner. Originally identified as a mini-cell locus in Bacillus subtilis, DivIVA is known to have dual functions in the regulation of cell division in this organism. In vegetatively growing cells, it is required for appropriate septum placement through interacting with and confining the MinCD cell division inhibitory complex at the cell poles (Cha \& Stewart, 1997; Marston \& Errington, 1999). In sporulating cells, it facilitates chromosome segregation by interacting with the oriC complex (Thomaides et al., 2001).

DivIVA in B. subtilis is not essential, but its inactivation produces mini-cells, and its overexpression produces filamentous cells (Cha \& Stewart, 1997). In contrast, in Streptomyces coelicolor, DivIVA $\mathrm{SC}_{\mathrm{S}}$ is essential and is localized to the growing tips and lateral branches of hyphae where nascent peptidoglycan synthesis occurs (Flardh, 2003). Partial depletion of $\operatorname{divIVA_{SC}}$ in this species causes defects in hyphal growth, with normal septum formation. Overexpression produces hyperbranching, with broad cells and abnormal tip growth, suggesting that DivIVA $_{S C}$ is important for morphogenesis rather than for correct septum formation or nucleoid localization. DivIVA homologues in other Gram-positive bacteria, including Brevibacterium lactofermentum and Enterococcus faecalis, are essential, and overexpression of this gene in these species results in enlarged cells (Ramirez-Arcos et al., 2005; Ramos et al., 2003).

These studies on DivIVA homologues suggest that Wag31 may be involved in septum formation, cell wall synthesis and/or chromosome segregation in mycobacteria. Our previous work using phosphomimetic and non-phosphorylatable forms of Wag31 suggested that the activity of Wag31 is regulated by phosphorylation. Overexpression of wild-type $w a g 31_{M t b}$ or a wag31 allele (wag31T73E $E_{M t b}$ ) encoding a phosphomimetic protein produced cells that were more rounded than control cells containing the vector alone or expressing a wag31 allele (wag31T73A $A_{M t b}$ ) encoding a protein in which the phosphoacceptor residue was changed to alanine.

Here we investigate the localization and function of Wag31 in mycobacteria, and the role of phosphorylation in modulation of its function. We demonstrate that Wag31 is highly localized to the cell poles. We further show that wag31 is essential in mycobacteria and that depletion of Wag31 causes a striking morphological change in which one end of the cell becomes round rather than rod-shaped. We demonstrate that this abnormal morphology appears to be caused by a defect in polar peptidoglycan synthesis. Finally, expression of $w a g 31_{M t b}$ in the wag31 conditional mutant of $M$. smegmatis altered the growth rate in a manner dependent on the phospho-acceptor residue encoded by the allele being expressed. These results indicate that Wag31 regulates growth, cell shape and cell wall synthesis in mycobacteria. The involvement of phosphorylation has not been shown in DivIVA homologues in other prokaryotes. This novel finding suggests a molecular mechanism by which the function of Wag31 in regulating these processes in $M$. tuberculosis can be modulated in response to environmental signals.

\section{METHODS}

Bacterial strains, media, and growth conditions. M. smegmatis and Mycobacterium bovis BCG cultures were grown at $37{ }^{\circ} \mathrm{C}$ in Middlebrook 7H9 liquid medium (Difco) supplemented with $10 \%$ $\mathrm{ADC}[\mathrm{ADC}=5 \%(\mathrm{w} / \mathrm{v}) \mathrm{BSA}$ fraction $\mathrm{V}, 2 \%(\mathrm{w} / \mathrm{v})$ glucose and $0.85 \%$ $(\mathrm{w} / \mathrm{v}) \mathrm{NaCl}$, and $0.05 \%(\mathrm{w} / \mathrm{v})$ Tween-80 (7H9-ADC-Tw), or on Middlebrook 7H9-ADC agar plates. Kanamycin $\left(50 \mu \mathrm{g} \mathrm{ml}^{-1}\right)$, hygromycin $\left(50 \mu \mathrm{g} \mathrm{ml}^{-1}\right)$ or apramycin $\left(50 \mu \mathrm{g} \mathrm{ml}^{-1}\right)$ was added to culture media as indicated. For growth analysis of the wag31 conditional mutant of $M$. smegmatis, cells were incubated on 7H9ADC agar plates containing $0.1 \%(\mathrm{w} / \mathrm{v})$ acetamide, then reinoculated onto fresh 7H9-ADC agar plates with or without $0.1 \%$ acetamide. For growth analysis in liquid medium, the wag31 conditional mutant cells grown on 7H9-ADC agar plates containing $0.1 \%$ acetamide or $5 \mathrm{ng}$ tetracycline $\mathrm{ml}^{-1}$ were inoculated into fresh $7 \mathrm{H} 9-\mathrm{ADC}$ liquid medium without inducer and cultured overnight to deplete the 
inducer and functional Wag31 protein inside the cell. Then, cells were reinoculated into 7H9-ADC liquid medium with or without inducer $\left(0.1 \%\right.$ acetamide or $2 \mathrm{ng}$ tetracycline $\left.\mathrm{ml}^{-1}\right)$, followed by $\mathrm{OD}_{600}$ measurement. Escherichia coli DH5 $\alpha$ (Life Technologies) was used as a host strain for cloning experiments, and was grown in LB broth or solid medium with kanamycin $\left(25 \mu \mathrm{g} \mathrm{ml}^{-1}\right)$ or apramycin $(50 \mu \mathrm{g}$ $\mathrm{ml}^{-1}$ ) added where appropriate.

Plasmid construction. For localization of Wag31 in wild-type $M$. smegmatis, the $g f p-w a g 31_{M s m e g}$ construct was subcloned behind the acetamide-inducible promoter in an integrating plasmid pMV306 $\left(\mathrm{Km}^{\mathrm{R}}\right)$, which contains the attachment site $(\mathrm{attP})$ and integrase (int) of mycobacteriophage L5 and integrates into the chromosomal attB attachment site (Hess et al., 1998; Lee et al., 1991; Parish et al., 1997). Two-step PCR was conducted to make $g f p-w a g 31_{M s m e g}$. First, the $g f p$ gene was amplified by PCR using pTracerCMV (Invitrogen) as the template and the Ngfp-wag-1 and Ngfp-wag-2 primers. All primer sequences are shown in Supplementary Table S1. All PCR products were sequenced to verify the absence of mutations. The wag31 gene from M. smegmatis was also amplified using chromosomal DNA from wild-type M. smegmatis and the Ngfp-wag-3 and Ngfp-wag-4 primers. Using the above two PCR products and Ngfp-wag- 1 and Ngfp-wag-4 primers, the second overlap PCR was conducted to produce $g f p-$

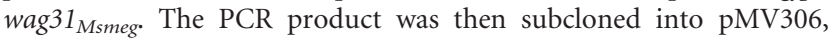
which contained the acetamidase promoter. As a control, the $g f p$ gene alone was cloned into pMV306 using Ngfp-wag-1 and N-gfp-2 primers. In addition, to examine the localization of Wag $31_{\mathrm{Mtb}}, g f \mathrm{p}-$ wag $31_{M t b}$ was similarly cloned into pMV306 using Ngfp-wag-1, NgfpTBwag-2, Ngfp-TBwag-3 and Ngfp-TBwag-4 primers. pMV306- $\mathrm{P}_{\text {acet }}{ }^{-}$ $g f p-w a g 31_{M s m e g}$ was transformed into wild-type M. smegmatis, and pMV306- $\mathrm{P}_{\text {acet }}-g f p-w a g 31_{M t b}$ was transformed into M. bovis BCG. To examine the localization of GFP-Wag $31_{\mathrm{Msmeg}}$ in the wag31 conditional mutant, the $\mathrm{P}_{\text {acet }}-g f p-$ wag $31_{\text {Msmeg }}$ construct from pMV306$\mathrm{P}_{\text {acet }}-g f p-w a g 31_{M s m e g}$ was subcloned into the replicating plasmid pMV261 $\left(\mathrm{Km}^{\mathrm{R}}\right)$. This construct was then introduced into the wag31 conditional mutant containing wild-type wag $31_{\text {Msmeg }}$ under the tetracycline-inducible promoter (see below).

The deletion construct for wag31 in M. smegmatis was made in the integrating plasmid pRH1351 that contains a $s a c B$ counterselection marker, a gentamicin-resistance gene, and a temperature-sensitive mycobacterial replication origin (Pelicic et al., 1997; Raman et al., 2001). The upstream 971 bp region of the wag31 gene, including the first 28 codons of Wag31, was amplified by PCR from M. smegmatis chromosomal DNA using Ms-wag31-cond-1 and Ms-wag31-cond-2 primers. The downstream $842 \mathrm{bp}$ of wag31, which includes the final 43 codons, was amplified using Ms-wag31-cond-3 and Mswag31-cond-4 primers. The second PCR was conducted using the two PCR products and Ms-wag31-cond-1 and Ms-wag31-cond-4 primers. This construct was subcloned into pRH1351. Finally, a hygromycin-resistance gene was inserted between two wag31 flanking regions.

Construction of the wag31 conditional mutant strains. First, the plasmid that contains the wild-type wag31 gene under the control of the acetamide-inducible promoter (pMV306- $\mathrm{P}_{\text {acet }}-$ wag31 $1_{\text {Msmeg }}$ ) was integrated into the L5 attB locus of wild-type M. smegmatis (Kang et al., 2005). The wag31 deletion construct described above was transformed into this strain. To facilitate homologous recombination, transformant cells were cultured in 7H9 liquid medium containing hygromycin at $30{ }^{\circ} \mathrm{C}$ for 3 days, then plated onto $7 \mathrm{H} 9$ agar plates with hygromycin and $10 \%$ sucrose and incubated at $39^{\circ} \mathrm{C}$. Thirty colonies were picked and genomic DNA was purified from these. Four out of 30 candidates produced the correct size of PCR product $(2.15 \mathrm{~kb})$ for the wag31 insertion/deletion; wild-type control DNA produced a $1.55 \mathrm{~kb}$ PCR product when Ms-wag31-cond-1 and Mswag 31-2 primers were used.
To express $g f p$-wag31 or wild-type wag31 in a wag31 conditional mutant, we constructed a new conditional mutant strain that contained the wag $31_{\text {Msmeg }}$ gene under the control of a tetracyclineinducible promoter. To do this, we subcloned the wag $31_{M s m e g}$ gene behind $\mathrm{P}_{\text {tet }}$ of the pMind plasmid (Blokpoel et al., 2005). The $\mathrm{P}_{\text {tet }}{ }^{-}$ wag $31_{\text {Msmeg }}$ region was then subcloned into an integration vector pMH94A $\left(\right.$ Apra $\left.^{\mathrm{R}}\right)$. The resulting construct was then transformed into the previous wag31 conditional mutant to replace the $\mathrm{P}_{\text {acet }}-$ wag $31_{\text {Msmeg }}$ with $\mathrm{P}_{\text {tet }}-$ wag $31_{\text {Msmeg }}$ at the L5 attB locus (Pashley \& Parish, 2003). Approximately half of the $\mathrm{Tet}^{\mathrm{R}}$, $\mathrm{Apra}^{\mathrm{R}}$ transformants could not grow on $7 \mathrm{H} 9$ agar medium containing kanamycin and $0.1 \%$ acetamide, confirming the replacement of pMV306- $\mathrm{P}_{\text {acet }}{ }^{-}$ wag31 Msmeg $\left(\mathrm{Km}^{\mathrm{R}}\right)$ with pMH94- $\mathrm{P}_{\text {tet }}-$ wag31 $1_{\text {Msmeg }}\left(\right.$ Apra $\left.^{\mathrm{R}}\right)$. We then electroporated pMV261- $\mathrm{P}_{\text {acet }}-g f p-w a g 31_{\text {Msmeg }}\left(\mathrm{Km}^{\mathrm{R}}\right)$ into this conditional mutant of wag31. Construction of the additional conditional mutants of wag31 in which $\mathrm{P}_{\text {acet }}{ }^{- \text {wag } 31} 1_{\text {Msmeg }}$ was replaced with $\mathrm{P}_{\text {tet }}{ }^{-}$ wag $31_{M t b}$, $\mathrm{P}_{\text {tet }}-w a g 31 T 73 A_{M t b}$ or $\mathrm{P}_{\text {tet }}-w a g 31 T 73 E_{M t b}$ was performed similarly.

Microscopic analysis of Wag31 localization, cell morphology, nascent peptidoglycan synthesis and chromosome segregation. For cellular localization of Wag31, pMV306- $\mathrm{P}_{\text {acet }}-g f p-$ wag $31_{\text {Msmeg }}$ or pMV306- $\mathrm{P}_{\text {acet }}-g f p$ was electroporated into wild-type M. smegmatis. The resulting strains were grown in $7 \mathrm{H} 9$ liquid medium containing $0.1 \%$ acetamide for $7 \mathrm{~h}$, transferred onto glass slides and observed using an Olympus BX51 fluorescence microscope equipped with a $\times 100$ differential interference contrast (DIC) oil UPLAPO objective and fluorescence filter set. Photographs were taken with an Olympus DP30BW high-sensitivity cooled charge-coupled device (CCD) camera, acquired with DP-BSW software and processed with Adobe Photoshop CS2. For the localization of GFP-Wag $31_{\mathrm{Mtb}}$ in M. bovis BCG, transformant cells were induced with $0.1 \%$ acetamide for $16 \mathrm{~h}$ before examination by microscopy.

For observation of morphological changes and nascent peptidoglycan synthesis in the wag31 conditional mutant during gradual depletion of Wag31, cells grown on $7 \mathrm{H} 9$ agar medium with $0.1 \%$ acetamide were inoculated into fresh 7H9 liquid medium without inducer. At 5, 22 and $46 \mathrm{~h}$ of incubation with shaking, $1 \mathrm{ml}$ of cells was treated with $5 \mu \mathrm{g}$ Van-Alexa568, and incubated for a further $2 \mathrm{~h}$. A $5 \mathrm{mg} \mathrm{ml}^{-1}$ stock of Van-Alexa568 (vancomycin-Alexa568 conjugate) was synthesized according to the manufacturer's manual (Alexa Fluor 568 protein labelling kit, Molecular Probes). Cells were then washed with $7 \mathrm{H} 9$ liquid medium and examined by microscopy. To study nascent peptidoglycan synthesis in wild-type M. smegmatis, exponentially growing cells were incubated with $1 \mu \mathrm{g}$ Van-Alexa658 $\mathrm{ml}^{-1}$ for $7 \mathrm{~h}$ and examined by fluorescence microscopy.

For co-localization of GFP-Wag31 and nascent peptidoglycan synthesis, wild-type $M$. smegmatis cells containing pMV306- $\mathrm{Pacet}^{-}$ $g f p-w a g 31_{\text {Msemg }}$ were cultured in 7H9 liquid medium with kanamycin and $0.1 \%(\mathrm{w} / \mathrm{v})$ acetamide. After $6 \mathrm{~h}$ incubation with shaking $\left(\mathrm{OD}_{600}=0.5\right)$, cells were treated with $1 \mu \mathrm{g}$ Van-Alexa568 $\mathrm{ml}^{-1}$, and further incubated for $3.5 \mathrm{~h}$. Cells were then washed with 7H9 liquid medium and examined by microscopy.

To test the effect of Wag31 on chromosome segregation, wag31 conditional mutant cells were stained with cell-permeant SYTO dye (SYTO Blue Fluorescent Nucleic Acid Stains kit, Molecular Probes). A series of SYTO dyes was tested to determine the optimal dye for DNA staining in M. smegmatis. SYTO 45 was chosen since it produced a strong signal with minimal bleaching. To evaluate the effect of Wag31 on chromosome segregation, wag31 conditional mutant cells were cultured with or without $0.1 \%$ acetamide. After $7 \mathrm{~h}$ incubation with shaking, each culture $(1 \mathrm{ml})$ was treated with $5 \mu \mathrm{M}$ SYTO 45 for $30 \mathrm{~min}$, washed with fresh $7 \mathrm{H} 9$ liquid medium, and examined by microscopy. 
Immunoblot analysis. To examine Wag31 in the wag31 conditional mutant, cells cultured with or without inducer $(0.1 \%$ acetamide $)$ were harvested after $48 \mathrm{~h}$ of shaken incubation. After washing with $40 \mathrm{mM}$ Tris buffer ( $\mathrm{pH}$ 7.5), total protein was extracted using TRIzol (Invitrogen), Lysing Matrix B tubes (QBiogene) and the MagNA Lyser device (Roche). A $5 \mu \mathrm{g}$ sample of total protein from each culture was used for immunoblot analysis using the anti-Wag31 mAb (Hermans et al., 1995) and the Phototope-HRP Western Blot Detection System (Cell Signaling Technology).

To examine Wag31 content in strains expressing three different wag31 alleles $\left(w a g 31_{M t b}\right.$, wag3 $1 T 73 A_{M t b}$ and wag31T73E $\left.E_{M t b}\right)$ in the wag31 conditional mutant, each strain was cultured in 7H9 liquid medium without tetracycline overnight and then inoculated into a fresh $7 \mathrm{H} 9$ liquid medium containing $2 \mathrm{ng}$ tetracycline $\mathrm{ml}^{-1}$. Total protein was purified from 26 and $53 \mathrm{~h}$ cultures and $5 \mu \mathrm{g}$ total protein was used for Western blot analysis with anti-Wag $31 \mathrm{mAb}$. Protein from exponentially growing $M$. smegmatis wild-type cells was used as a control.

The levels of the Wag31 protein and its phosphorylation at different growth stages of $M$. bovis BCG were determined by Western blot analysis with the anti-Wag31 mAb and a phospho-Q (Durocher et al., 2000) polyclonal antibody (Cell Signaling Technology). Wild-type $M$. bovis BCG cells were cultured in 7H9 liquid medium, and total protein from mid-exponential, late-exponential, early-stationary and late-stationary phase cells was purified as described above. Western blot analysis with the anti-Wag31 $\mathrm{mAb}$ was conducted by running $5 \mu \mathrm{g}$ protein in a SDS-PAGE gel $(10 \% \mathrm{Tris} / \mathrm{HCl})$. Because the phosphorylation level of Wag31 has been found previously to be very low in M. tuberculosis (Kang et al., 2005), 10-fold more protein $(50 \mu \mathrm{g})$ was used to detect changes in Wag31 phosphorylation.

\section{RESULTS}

\section{Wag31, a member of the division cell wall ( $d c w)$ cluster, is recruited to new cell poles when cell division is completed or nearly completed}

Many Gram-positive and Gram-negative bacteria possess a chromosomal region that contains several genes whose products are involved in cell division and cell wall biosynthesis, and is therefore known as the $d c w$ cluster (Massidda et al., 1998; Pucci et al., 1997; Yura et al., 1992). Supplementary Fig. S1 shows that in M. tuberculosis, wag31 is part of the $d c w$ gene cluster that contains cell division genes ( $f t s Z, f t s Q$ and $f t s W$ ) and peptidoglycan biosynthetic genes (murC, murG, murD, murX, murF and murE). The location of wag31 in this cluster suggests that Wag31 plays a role in cell division and/or cell wall synthesis. The gene encoding Wag31 (Rv2145c) is separated by 268 bp from Rv2146c and by 95 bp from Rv2144c, suggesting that wag31 is monocistronic. In support of this inference we identified a transcription start site $5^{\prime}$ of wag 31 and $3^{\prime}$ of the upstream gene Rv2146c (data not shown).

In vegetatively growing $B$. subtilis cells, the Wag31 homologue DivIVA localizes to the cell poles and the septum, where it is bound to the MinCD cell division inhibitor complex so that the FtsZ ring can only form at the mid-cell region (Marston et al., 1998). After assembly of the FtsZ ring, DivIVA is recruited to the mid-cell division site before contraction of the ring begins (Edwards \& Errington, 1997). To see if a similar pattern of Wag31 localization occurs in mycobacteria, we constructed and expressed a $g f p-w a g 31_{\text {Msmeg }} \mathrm{N}$-terminal fusion driven by an acetamide-inducible promoter in the integrating vector pMV306 (Parish et al., 1997) in M. smegmatis, and examined it by fluorescence microscopy.

Growth in the presence of the inducer $(0.1 \%$ acetamide $)$ for $7 \mathrm{~h}$ showed normal cell morphology and revealed strong, distinct localization of GFP-Wag $31_{\mathrm{Msmeg}}$ at the poles but very little at the potential mid-cell position (Fig. 1). The signal was often markedly stronger at one of the poles (the old pole) in cells that were in the process of dividing and in newly formed daughter cells (Fig. 1a, b). Such localized structures were not seen when GFP alone was expressed, indicating that the GFP-Wag $31_{\mathrm{Msmeg}}$ localization is not a GFP artefact (Fig. 1c). These findings suggest that the role of Wag31 in mycobacteria is distinct from that of DivIVA in $B$. subtilis, which has been found to localize at cell poles and at the mid-cell position before cell division. To determine whether Wag31 localized in a similar manner in the slowgrowing members of the $M$. tuberculosis complex, we constructed an $\mathrm{N}$-terminal $g f p-w a g 31_{M t b}$ fusion protein from M. tuberculosis and expressed it in M. bovis BCG. When examined after $16 \mathrm{~h}$ of induction with $0.1 \%$ acetamide, GFP-Wag $31_{\mathrm{Mtb}}$ showed localization patterns identical to those seen with GFP-Wag31 $1_{\text {Msmeg }}$ (Fig. 1a, inset).

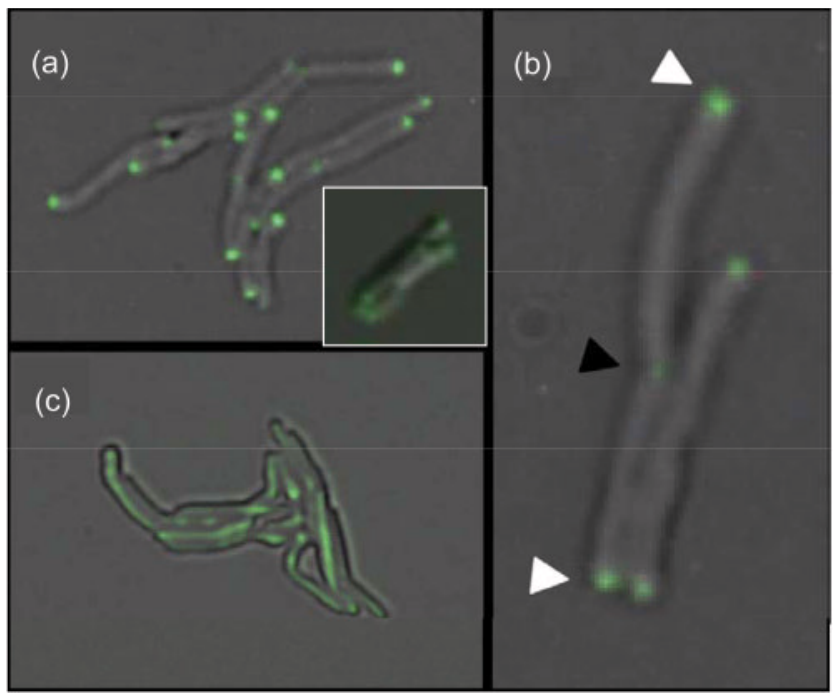

Fig. 1. Localization of GFP-Wag31 in M. smegmatis. Images from bright-field DIC and fluorescence microscopy of GFPWag $31_{\text {Msmeg }}$ were overlapped. The gene for gfp or gfp-wag31 was expressed for $7 \mathrm{~h}$ under the control of the inducible acetamidase promoter. (a) M. smegmatis strain expressing gfpwag $31_{\text {Msmeg}}$; inset, M. bovis BCG expressing gfp-wag $31_{M t b}$. (b) Magnified image of cells expressing gfp-wag3 1 Msmeg. White triangles indicate GFP-Wag31 smeg signals from the cell poles, and the black triangle indicates a weaker signal where cell division is completed or near completion. The adjacent cell does not have a signal from the mid-cell region. (c) Control M. smegmatis strain expressing gfp alone. 


\section{wag31 is essential in mycobacteria}

In a saturation transposon mutagenesis study in $M$. tuberculosis, no wag31 insertions were isolated, suggesting that wag31 is essential (Sassetti et al., 2003). To verify that it is essential, and to examine the role of Wag31 in mycobacteria, we constructed a conditional mutant of wag31 in $M$. smegmatis by disrupting the wag31 chromosomal locus in the presence of a construct that expresses wag $31_{\text {Msmeg }}$ from the acetamide-inducible promoter $\mathrm{P}_{\text {acet }}$ (see Supplementary Fig. S2). The chromosomal wag31 gene was disrupted in a two-step process. First, the wag31 inducible expression construct in the integrating vector pMV306 (Parish et al., 1997) was electroporated into wildtype M. smegmatis. Transformants were selected and screened by PCR to confirm the presence of the second copy of wag31 (Supplementary Fig. S2, step A).

To inactivate the native copy of wag31 in this strain, 212 codons of wag31 were deleted and replaced with a hygromycin-resistance cassette. This construct was cloned into pRH1351 (Pelicic et al., 1997; Raman et al., 2001) and then electroporated into the strain resulting from step (A) (Supplementary Fig. S2). Sequential selection and counterselection yielded candidate strains in which the native chromosomal copy of wag31 was deleted. Disruption of the chromosomal wag31 was confirmed by PCR (Supplementary Fig. S2b).
To determine whether wag31 is essential in M. smegmatis, the conditional mutant was plated onto $7 \mathrm{H} 9$ solid medium with or without $0.1 \%$ acetamide. Fig. 2 (a) shows that the wag31 conditional mutant is unable to grow in the absence of Wag31 (no inducer), confirming that wag31 is an essential gene in M. smegmatis. To further examine the effect of Wag31 depletion on mycobacterial growth, the wag31 conditional mutant was cultured in $7 \mathrm{H} 9$ liquid medium in the presence or absence of $0.1 \%$ acetamide (Fig. 2b). To observe the effects of conditional depletion of Wag31 would require turnover of existing functional protein. The conditional wag31 mutant was therefore grown to mid-exponential phase $(16 \mathrm{~h})$ in the absence of inducer, prior to inoculation into medium with or without acetamide. While cells with inducer showed normal growth kinetics, the culture lacking the inducer did not display an increase in optical density. Finally, to confirm that this growth phenotype is due to the depletion of Wag31, immunoblot analysis with an anti-Wag31 mAb (Hermans et al., 1995) was performed. Cultures grown with or without inducer (Fig. 2b) were harvested at $48 \mathrm{~h}$, and total protein was purified for subsequent SDS-PAGE and Western blot analysis. Fig. 2(c) shows that while cells cultured with inducer produced Wag31, cells without inducer contained amounts of Wag31 that were nearly undetectable, confirming the linkage between the absence of Wag31 and the growth defect in the conditional mutant. (a)

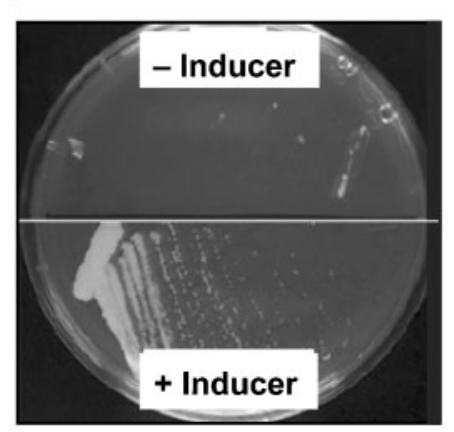

(b)

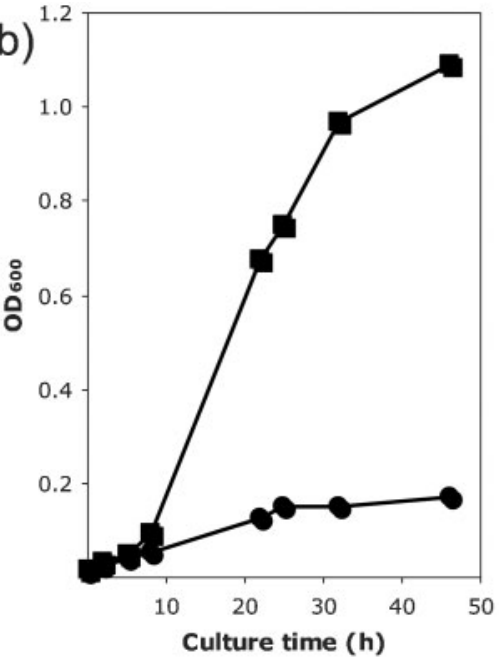

(c)

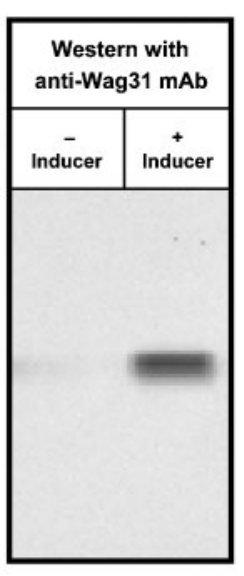

Fig. 2. wag31 is an essential gene in mycobacteria. (a) Growth of the M. smegmatis wag31 conditional mutant on $7 \mathrm{H} 9$ solid medium. Cells grown on $7 \mathrm{H} 9$ agar medium with $0.1 \%$ acetamide (inducer of wag31 expression) were streaked on fresh $7 \mathrm{H} 9$ agar plates with or without $0.1 \%$ acetamide. (b) Growth of the wag31 conditional mutant in $7 \mathrm{H} 9$ liquid medium. Colonies were grown in the presence of inducer on 7H9 agar plates and then cultured overnight in 7H9 liquid medium in the absence of acetamide. Cells were then reinoculated into liquid medium with (ם) or without ( $0.1 \%$ acetamide, and growth was monitored by measurement of $\mathrm{OD}_{600}$. (c) Western blot analysis for Wag31 in the wag31 conditional mutant. A $5 \mu \mathrm{g}$ sample of total protein from cultures at the $48 \mathrm{~h}$ time point in (b) was run in SDS-PAGE, followed by immunoblotting with an anti-Wag31 $\mathrm{mAb}(\mathrm{F} 126-2)$. 


\section{Depletion of wag31 causes a morphological phenotype with asymmetric bulged and round cells}

To test whether Wag31 depletion causes any morphological change in $M$. smegmatis, the wag31 conditional mutant grown on $7 \mathrm{H} 9$ agar medium containing $0.1 \%$ acetamide was inoculated into 7H9 liquid medium without acetamide, harvested at serial time points and examined by microscopy (Fig. 3, DIC $1 \times$ and DIC $2 \times$ ). After $7 \mathrm{~h}$, the majority of cells had a bulged tip at one end. Some cells appeared to be in the process of cell division despite the markedly abnormal bulged-tip morphology. At later stages of Wag31 depletion ( 24 and $48 \mathrm{~h}$ ), many cells became more rounded and many formed diplococcus-like cells, suggesting incomplete cell division. In addition, we observed that many cells appeared to have lysed, forming large clumps, suggesting that the morphological defect caused by Wag31 depletion produced osmotic instability, consistent with altered cell wall integrity.

In the wild-type background we found that GFPWag $31_{\text {Msmeg }}$ was localized at the cell pole immediately before or after the actual separation into two daughter cells (Fig. 1). We therefore examined whether the observed morphological changes of the wag31 conditional mutant are caused by the absence of Wag31 in the rounded end of the cells by observing the localization of GFP-Wag $31_{\mathrm{Msmeg}}$ in the wag31 conditional mutant. To do this, we subcloned the $\mathrm{P}_{\text {acet }}-g f p-w a g 31_{M s m e g}$ construct (from pMV306- $\mathrm{P}_{\text {acet }}{ }^{-}$ $g f p-w a g 31_{\text {Msmeg }}$ used in Fig. 1) into a replicating plasmid, pMV261 $\left(\mathrm{Km}^{\mathrm{r}}\right)$, and introduced this construct into a wag31 conditional mutant strain in which $\mathrm{P}_{\text {acet }}-$ wag $31_{\text {Msmeg }}$ was replaced with $\mathrm{P}_{\text {tet }}-$ wag $31_{\text {Msmeg }}$ (Blokpoel et al., 2005; see Methods). Transformants were selected and cultured on $7 \mathrm{H} 9$ solid medium with $0.1 \%$ acetamide and $10 \mathrm{ng}$ tetracycline $\mathrm{ml}^{-1}$. Cells were then inoculated into $7 \mathrm{H} 9$ liquid medium without either inducer and examined by microscopy as the residual Wag31 was depleted. When examined at about $6 \mathrm{~h}$ after inoculation, in almost all the cells that retained the signal, GFP-Wag $31_{\mathrm{Msmeg}}$ was exclusively found at the tip of the rod-shaped part of the cell, as shown in Fig. 3b (-inducer). When both inducers were present in the medium, cells had normal morphology and GFP-Wag $31_{\text {Msmeg }}$ was localized to both tips of the
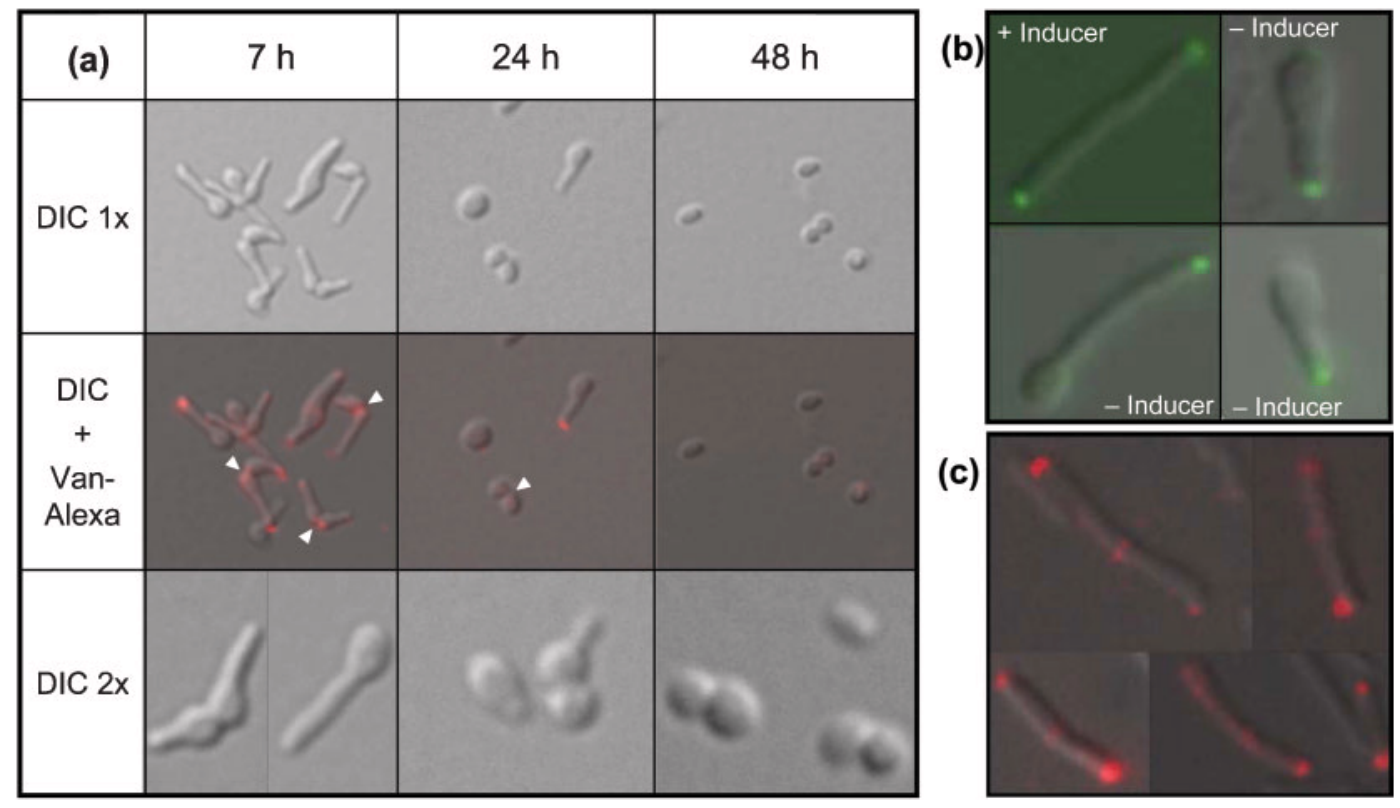

Fig. 3. Changes in morphology and peptidoglycan synthesis caused by the depletion of Wag31. (a) Morphological changes of the wag31 conditional mutant during growth without inducer. The wag31 conditional mutant cells grown on $7 \mathrm{H} 9$ solid medium containing $0.1 \%$ acetamide were inoculated into fresh $7 \mathrm{H} 9$ medium without inducer. Aliquots of culture were treated with $5 \mu \mathrm{g}$ Van-Alexa568 $\mathrm{ml}^{-1}$ at 5, 22 and $46 \mathrm{~h}$, incubated for another $2 \mathrm{~h}$, washed and examined by microscopy. DIC $1 \times$, DIC images using $\times 100$ objective lens; DIC + Van-Alexa, images for DIC and fluorescent Van-Alexa568 are superimposed; DIC 2×, images produced using a $\times 100$ objective lens magnified twofold by imaging software (Photoshop CS2). White triangles indicate VanAlexa568 signals found between the two seemingly dividing lollipop-shaped cells. (b) The bulged-tip phenotype is associated with the absence of Wag31. gfp-wag31 was expressed from the acetamide-inducible promoter in a wag31 conditional mutant in which native wag31 was expressed from a tetracycline-inducible promoter. Cells were cultured on $7 \mathrm{H} 9$ solid medium containing $10 \mathrm{ng}$ tetracycline $\mathrm{ml}^{-1}$ and $0.1 \%$ acetamide, and inoculated into fresh $7 \mathrm{H} 9$ liquid medium without either inducer. After $7 \mathrm{~h}$, cells were harvested, washed and examined by microscopy. (c) Examination of nascent peptidoglycan synthesis using Van-Alexa568 in wild-type M. smegmatis. Exponentially growing M. smegmatis cells were treated with $5 \mu \mathrm{g}$ Van-Alexa568 $\mathrm{ml}^{-1}$ for $2 \mathrm{~h}$, washed and examined by fluorescence microscopy. 
rod-shaped cell (Fig. 3b, +inducer). A portion of cells $(<30 \%)$ that had a bulged tip did not show any signal from GFP-Wag $31_{\text {Msmeg, }}$, suggesting that these cells may have been lysed and lost GFP-Wag $31_{\mathrm{Msmeg}}$.

\section{The bulged-tip phenotype of the wag31 conditional mutant is caused by the absence or dispersal of peptidoglycan synthesis}

In our previous work, we showed that overexpression of wag31 produced a large number of short, wide cells compared with control cells containing vector only (Kang et al., 2005). Here we have shown that depletion of wag31 causes abnormal morphology with a bulged tip at one end of the cell. These phenotypes could result from altered localization of peptidoglycan synthesis and/or cell division proteins. To examine whether Wag31 is present at the site of nascent peptidoglycan synthesis we first identified the site of nascent cell wall synthesis in wild-type $M$. smegmatis cells by using a fluoresceinated vancomycin conjugate (Van-Alexa568, red fluorescence; see Methods). Vancomycin binds the terminal D-Ala-D-Ala of the peptidoglycan precursor, and a vancomycin-fluorescein conjugate (Van-FL) has been used to identify the sites of nascent peptidoglycan synthesis during cell division in Gram-positive bacteria (Daniel \& Errington, 2003).

Using conditions similar to those used to localize the sites of nascent peptidoglycan synthesis in B. subtilis (Daniel \& Errington, 2003), no staining by Van-FL was detected in M. smegmatis. Because the lipid-rich mycobacterial cell envelope may be less permeable to this stain, we synthesized another vancomycin conjugate, Van-Alexa568 (Molecular Probes). Using the same concentration of VanAlexa568 $\left(1 \mu \mathrm{g} \mathrm{ml}^{-1}\right)$, prominent fluorescent labelling at the cell poles was evident after $7 \mathrm{~h}$ incubation, while weaker and dispersed fluorescent labelling was observed in the mid-cell regions (Fig. 3c). The staining pattern of VanAlexa568 in M. smegmatis was similar to that described for Van-FL staining of Corynebacterium glutamicum, a closely related actinomycete (Daniel \& Errington, 2003). While it is possible that differences in the lipid envelope between the cell pole and other parts of the cell result in this pattern of localized staining, these results strongly suggest that nascent peptidoglycan synthesis in mycobacteria occurs at the cell poles and mid-cell but not along the entire length of the rod.

We have shown in Fig. 1 that Wag31 is localized at the cell poles and is recruited to the mid-cell position when cell division is completed or nearly complete. This localization of Wag31 overlaps with the polar locus of nascent peptidoglycan synthesis, as shown in Fig. 3(c). We thus tested whether the bulged end of the wag31 conditional mutant was associated with a defect in peptidoglycan synthesis. To address this possibility, cells grown in 7H9 liquid medium without inducer to allow depletion of Wag31 (Fig. 3a, DIC $1 \times$ ) were treated with $5 \mu \mathrm{g}$ VanAlexa568 $\mathrm{ml}^{-1}$ for $2 \mathrm{~h}$, washed and then examined by fluorescence microscopy. After $7 \mathrm{~h}$ of Wag31 depletion, a strong Van-Alexa568 signal (nascent peptidoglycan synthesis) could be detected from the normal rod-shaped tip. In contrast, the bulged area which lacks GFP-Wag31, as shown in Fig. 3(b), showed an absent or very dispersed Van-Alexa568 signal (Fig. 3a, DIC+Van-Alexa). Taken together, these data suggest that the absence of Wag31 causes a defect in polar peptidoglycan synthesis, which in turn results in the bulged-tip morphology. In many cases, Van-Alexa568 signals (white triangles) were found between the two seemingly dividing lollipop-shaped cells, indicating active cell wall synthesis at the septal locus. Consistent with this interpretation, as cells became more rounded, as shown after 24 and $48 \mathrm{~h}$ of Wag31 depletion, VanAlexa568 did not show localized staining, suggesting absent or highly dispersed cell wall synthesis. At these later time points, many cells were in the form of fused diplococci, indicating that these cells were defective in completing cell division.

\section{Location and intensity of Wag31 staining correspond to those of nascent peptidoglycan synthesis at cell poles in wild-type $M$. smegmatis}

Data from the wag31 conditional mutant stained with VanAlexa568 strongly suggested that Wag31 plays a critical role in regulating nascent peptidoglycan synthesis at cell poles. If this were the case, we hypothesized that there would be temporal and spatial correlation between Wag31 and nascent peptidoglycan synthesis in wild-type M. smegmatis cells. To address this hypothesis, wild-type $M$. smegmatis cells containing $\mathrm{P}_{\text {acet }}-g f p-w a g 31_{\text {Msmeg }}$ were cultured to exponential phase $\left(\mathrm{OD}_{600}=0.5\right)$ in $7 \mathrm{H} 9$ liquid medium with $0.1 \%$ acetamide and stained with Van-Alexa568 $(1 \mu \mathrm{g}$ $\mathrm{ml}^{-1}$ ) in order to examine the localization of both GFPWag31 and nascent peptidoglycan synthesis. Fig. 4 shows that the location and intensity of Van-Alexa568 staining correspond very closely to those of GFP-Wag31. This result strongly indicates that Wag31 plays a key role in localized peptidoglycan synthesis at cell poles in mycobacteria.

\section{Wag31 is not required for chromosome segregation}

In sporulating B. subtilis, DivIVA has been shown to be important in chromosome segregation through its interaction with the oriC complex (Thomaides et al., 2001). Since Wag31 is a homologue of DivIVA, we investigated whether Wag31 is also involved in chromosome segregation in mycobacteria, by staining DNA in the conditional wag31 mutant. To investigate the effect of Wag31 on chromosome segregation in mycobacteria, the wag31 conditional mutant cells were cultured in the presence or absence of the inducer $(0.1 \%$ acetamide). After $7 \mathrm{~h}$ incubation, $1 \mathrm{ml}$ of each culture was treated with $5 \mu \mathrm{M}$ of SYTO 45 (Molecular Probes) for $30 \mathrm{~min}$, washed with fresh 7H9 liquid medium, and examined by fluorescence microscopy. Cells grown in the presence of inducer showed 


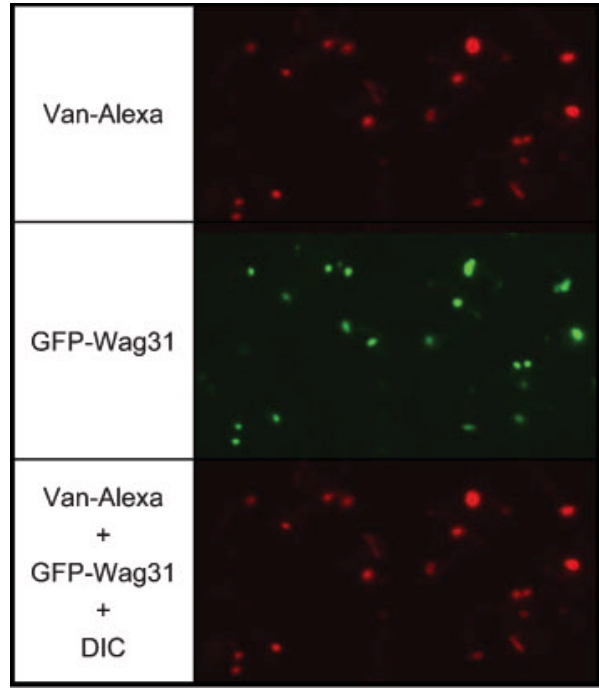

Fig. 4. Co-localization of GFP-Wag31 and nascent peptidoglycan synthesis. Wild-type M. smegmatis cells containing $\mathrm{P}_{\text {acet }}-g f p-$ wag31 were cultured to exponential phase in $7 \mathrm{H} 9$ liquid medium with $0.1 \%$ acetamide and stained with $1 \mu \mathrm{g} \mathrm{Van-Alexa568 \textrm {ml } ^ { - 1 }}$ for $3.5 \mathrm{~h}$. Cells were then washed and examined by fluorescence microscopy. Images from Van-Alexa568 staining are shown in red (upper row) and GFP-Wag31 signals are shown in green (middle row). The two fluorescent images were then overlapped with the bright-field DIC image (bottom row).

normal DNA segregation, with two distinct chromosomes separated by the septum of the rod-shaped cell (Fig. 5, + inducer). Cells without the inducer produced the bulged tip, and the bulged-tip area and the rounded cells were both stained with SYTO 45, suggesting that DNA segregation is not dependent on the presence of Wag31 in mycobacteria (Fig. 5, -inducer). While DNA is clearly present in both the rod-shaped and the round end of the cells, these data do not exclude a role for Wag31 in accurate chromosome segregation.

\section{Phosphorylation of Wag31 is important for optimal growth of $M$. smegmatis}

In our previous work, we showed that moderate overexpression of the wild-type wag $31_{M t b}$ or phosphomimetic wag31T73E $E_{M t b}$ in M. smegmatis produced cells that are more rounded than the control cells containing the nonphosphorylatable wag $31 \mathrm{~T} 73 A_{M t b}$ allele or the vector alone (Kang et al., 2005). The different morphological effects of these three wag $31_{M t b}$ alleles strongly suggested that phosphorylation of Wag31 plays an important role in its regulation of cell division/morphology in mycobacterial cells. To further study the function of Wag31 phosphorylation, we determined the effect of three wag $31_{M t b}$ alleles on growth of $M$. smegmatis by introducing and independently expressing the wild-type $w a g 31_{M t b}$, wag $31 T 73 A_{M t b}$ or wag $31 T 73 E_{M t b}$ alleles in the conditional wag31 mutant of

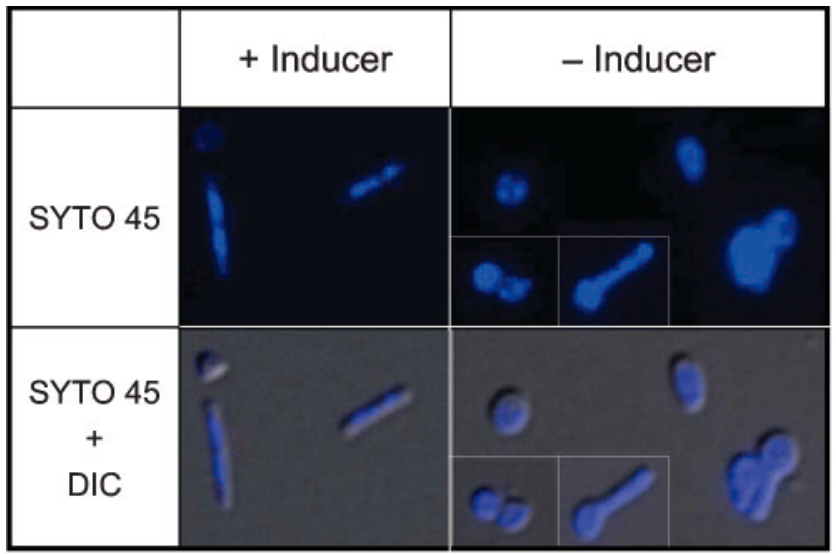

Fig. 5. Chromosome segregation in the wag31 conditional mutant. wag31 conditional mutant cells grown on $7 \mathrm{H} 9$ agar medium containing inducer $(0.1 \%$ acetamide) were inoculated into fresh $7 \mathrm{H} 9$ liquid medium in the presence or absence of the inducer. After $7 \mathrm{~h}$ of incubation with shaking, each culture $(1 \mathrm{ml})$ was treated with $5 \mu \mathrm{M}$ SYTO 45 for $30 \mathrm{~min}$, washed and examined by fluorescence microscopy. The upper row shows the fluorescent images of induced and uninduced cultures, and the lower row shows the superimposed images from DIC and fluorescence microscopy.

M. smegmatis. To do this, we constructed new conditional mutant strains of wag31 in which the acetamide-inducible $\mathrm{P}_{\text {acet }}-$ wag $31_{\text {Msmeg }}$ construct at the attB locus was replaced with tetracycline-inducible $\quad \mathrm{P}_{\text {tet }}-w a g 31_{M t b}, \quad \mathrm{P}_{\text {tet }^{-}}$ wag $31 T 73 A_{M t b}$ or $\mathrm{P}_{\text {tet }}-w a g 31 T 73 E_{M t b}$ (Pashley \& Parish, 2003). In the absence of tetracycline, none of the transformants could grow on solid 7H9 medium containing the appropriate antibiotics, confirming the low basal expression from the $\mathrm{P}_{\text {tet }}$ promoter. However, when plated on solid 7H9 medium containing $5 \mathrm{ng}$ tetracycline $\mathrm{ml}^{-1}$, all three transformants were able to grow. This result suggests that while Wag31 itself is essential for the survival of mycobacterial cells, the phosphorylation of Wag31 is not essential to the function of Wag31, but rather may be important for the fine-tuning of Wag31 function.

To examine in more detail the effect of phosphorylation of Wag31 on growth, each transformant was cultured overnight in 7H9 liquid medium in the absence of tetracycline and then inoculated into fresh $7 \mathrm{H} 9$ liquid medium containing $2 \mathrm{ng}$ tetracycline $\mathrm{ml}^{-1}$ (Fig. 6a). The choice of this concentration of tetracycline was based on preliminary growth experiments with different concentrations of tetracycline $\left(1-20 \mathrm{ng} \mathrm{ml}^{-1}\right.$ ) to identify the concentration that produced growth and Wag31 protein levels comparable to those in wild-type M. smegmatis (data not shown). During exponential phase, the wag31 conditional mutant containing $\mathrm{P}_{\text {tet }}-$ wag $31 T 73 E_{M t b}$ (mean doubling time, $g=4.30 \mathrm{~h}$ ) showed the highest growth rate, cells harbouring $\mathrm{P}_{\text {tet }}-w a g 31_{M t b}(g=4.95 \mathrm{~h})$ showed an intermediate growth rate, and cells with $\mathrm{P}_{\text {tet }}{ }^{-}$ wag $31 T 73 A_{M t b}(g=5.75 \mathrm{~h})$ showed the lowest growth rate. 
(a)

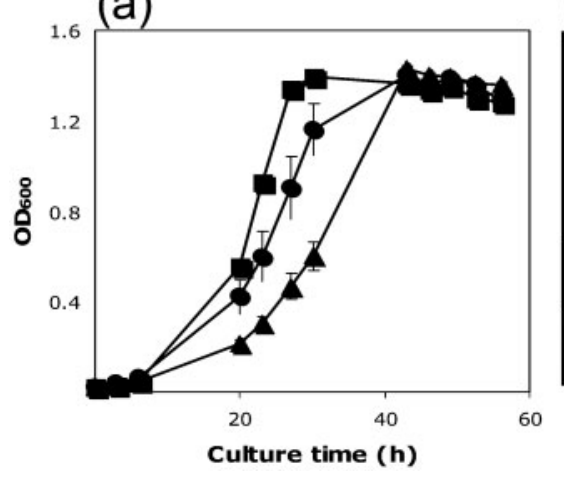

(b)

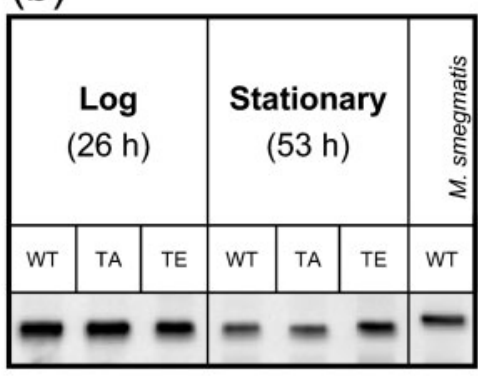

(c)

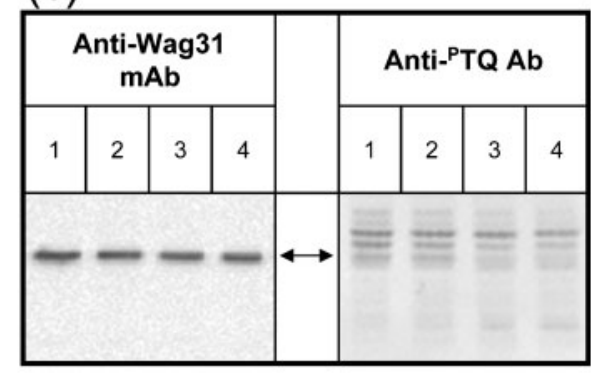

Fig. 6. Effect of Wag31 phosphorylation on growth of M. smegmatis. wag31 conditional mutants were constructed in which one of three wag3 $1_{M t b}$ alleles, $P_{\text {tet }}-$ wag31 $1_{M t b}$, $P_{\text {tet }}-$ wag31T73 $A_{M t b}$ or $P_{\text {tet }}-$ wag31T73E $E_{M t b}$, was expressed under the control of a tetracycline-inducible promoter. (a) Differential growth phenotypes among the three strains. Each strain was cultured in $7 \mathrm{H} 9$ liquid medium with $2 \mathrm{ng}$ tetracycline $\mathrm{ml}^{-1}$ and growth was examined by measuring $\mathrm{OD}_{600}$. These data were collected from three independent cultures of each strain containing $\mathrm{P}_{\text {tet }}-$ wag3 $31_{M t b}(\bullet), \mathrm{P}_{\text {tet }}-$ wag31T73A $A_{M t b}(\boldsymbol{\Delta})$ or $\mathrm{P}_{\text {tet }}-$ wag31T73E $E_{M t b}(\boldsymbol{\square})$. Error bars represent 1 SD. (b) Western blot analysis to examine Wag31 protein content in the strains expressing the three different wag31 alleles. Total protein was purified from exponential- $(26 \mathrm{~h})$ and stationary-phase cells $(53 \mathrm{~h})$, and $5 \mu \mathrm{g}$ of total protein was used for Western blot analysis with anti-Wag31 mAb. Protein from exponentially growing $M$. smegmatis wild-type cells is also shown, and demonstrates a Wag31 protein content similar to that in the inducible expression strains. (c) Levels of Wag31 and its phosphorylation (indicated by the double-headed arrow) at different growth stages of M. bovis BCG. For Western blot analysis with anti-Wag31 mAb, $5 \mu \mathrm{g}$ of total protein was loaded in each lane; for Western blot analysis with anti- ${ }^{\mathrm{P}}$ TQ antibody, $50 \mu \mathrm{g}$ per lane was used. Lanes: 1 , mid-exponential phase; 2, late exponential phase; 3, early stationary phase; 4, late stationary phase. In addition to Wag31, additional bands were detected by the anti- ${ }^{\mathrm{P}} \mathrm{TQ}$ antibody, consistent with our previous immunoblot data (Kang et al., 2005).

Western blot analysis with anti-Wag31 mAb confirmed that this growth phenotype is not due to differences in expression levels of each construct (Fig. 6b). When examined by microscopy, no clear difference in morphology was found among the three strains harvested at serial time points (data not shown).

In a Western blot analysis of cell lysates from different growth phases with anti-Wag31 mAb, we found that the wag31 gene was constitutively expressed from exponential through to stationary phase. Probing with an anti-phospho$(\mathrm{S} / \mathrm{T}) \mathrm{Q}$ antibody that recognizes the phosphorylation site in Wag31, however, we found that Wag31 is mainly phosphorylated during exponential phase in $M$. bovis BCG (Fig. 6c). This result is consistent with our previous finding that the $p k n A / B$ operon is maximally transcribed during exponential phase and that its transcription drops dramatically during stationary phase. In the context of these observations, the differential growth phenotypes of cells expressing wag31 alleles that encode substitutions at the phosphoacceptor site (Fig. 6a) suggest that precise regulation of Wag31 phosphorylation at different growth phases is important for optimal growth of mycobacteria.

\section{DISCUSSION}

In this work we determined that wag31 is an essential gene whose product localizes to cell poles, and that depletion of
Wag31 results in a dramatic morphological change in which one end of the cell becomes rounded. Together with data showing co-localization of GFP-Wag31 and nascent cell wall synthesis at the cell poles in both the wag31 conditional mutant and wild-type strains of M. smegmatis, these results indicate that Wag31 is important for maintaining cell shape and cell wall integrity by localizing peptidoglycan synthesis to the cell poles. This role in regulating cell wall synthesis is consistent with the chromosomal locus of wag31 being in the $d c w$ cluster, which includes six mur genes encoding enzymes that function in the biosynthesis of peptidoglycan precursor molecules.

While our data show that polar localization of Wag31 is critical for maintaining the rod shape of mycobacteria, Wag31 does not appear to play a major role in formation or function of the mid-cell division complex, in contrast to the function of DivIVA in some other species. In vegetatively growing $B$. subtilis cells, for example, the Wag31 homologue DivIVA localizes at the cell poles and the septum. At the cell poles, DivIVA-GFP is bound to the MinCD cell division inhibitor complex so that the FtsZ ring can only form at the mid-cell region (Marston et al., 1998). After assembly of the FtsZ ring, DivIVA then is recruited to the mid-cell division site before contraction of the ring begins (Edwards \& Errington, 1997). Our experiments in mycobacteria, however, which lack MinC or MinD homologues, revealed intense localization of 
GFP-Wag $31_{\text {Msmeg }}$ at the poles but not at the septum, suggesting that in mycobacteria Wag31 does not play a major role in septum formation. This idea is consistent with the hypothesis that peptidoglycan synthesis required for septation is independent from that required for cell elongation (Donachie \&Robinson, 1987).

What is the mechanism by which first one and then both ends of the cell lose their rod shape and become rounded when Wag31 is depleted? A previously described model for the generation of rod-shaped cells by actinomycetes such as mycobacteria proposes that de novo peptidoglycan synthesis limited to the cell poles gives rise to this shape, with progressive elongation of the rod until cell division occurs (Daniel \& Errington, 2003). Our data are strongly supportive of this model and indicate a critical role of Wag31 in the polar localization of peptidoglycan synthesis during cell growth. Our data also demonstrate an asymmetry in this process, with accumulation of Wag31 beginning at the new pole only at the final stages, or after completion, of cell division. Thus, the old pole shows a strong GFP-Wag31 signal and strong staining of nascent peptidoglycan by Van-Alexa, whereas the division site shows minimal GFP-Wag31 signal until after cytokinesis. In the wild-type, following cell division, Wag31 accumulates at the new pole, and the rod-shape is maintained by polar peptidoglycan synthesis at both poles. In the wag31 conditional mutant strain without ongoing wag31 expression, however, the new pole is unable to accumulate Wag31 and thus is unable to direct localized peptidoglycan synthesis to the new pole. In this model, the resulting absent or diffuse cell wall synthesis at the new pole, possibly caused by an imbalance between cell wall synthesis and cell wall hydrolysis, results in a round end of the cell while the other end (the old pole with residual Wag31) maintains its rod shape. Over time, residual Wag31 is depleted from the old pole, and the cells become completely round and more susceptible to lysis.

This model suggested by our data raises several questions for further investigation. What is the mechanism by which Wag31 localizes to the poles? How does it direct peptidoglycan synthesis? Does Wag31 recruit the cell wall synthesis machinery to the poles, or does it play some other regulatory role? Protein-protein interactions are likely to be critical to Wag31 localization and function, and this protein contains at least two predicted protein interaction domains (Flardh, 2003).

Another subject for investigation is the role of phosphorylation of Wag31 in modulating its function. The higher growth rate during exponential phase of the strains expressing the wag $31 T 73 E_{M t b}$ allele relative to those harbouring the wag $31_{M t b}$ or wag $31 T 73 A_{M t b}$ alleles suggests that regulation of the activity of Wag31 via phosphorylation is important during active cell growth in mycobacteria. This result is consistent with our previous and current data indicating that the expression levels of the kinase genes responsible for phosphorylating Wag31 ( $p k n A$ and $p k n B)$ are highest during exponential-phase growth, as is the extent of phosphorylation of Wag31 in vivo (Kang et al., 2005).

Our results thus identify and provide insights into a novel mechanism for the regulation of localized cell wall synthesis in mycobacteria via polar localization of Wag31. This function may then be further modulated by reversible phosphorylation in response to environmental conditions, including those encountered during infection. Wag31 and DivIVA homologous proteins have two predicted coiled-coil regions that are interrupted by a highly variable sequence (Flardh, 2003). Interestingly, this highly variable sequence contains the unique phosphorylation site of Wag31 (T73). None of the DivIVA homologues are known to be phosphorylated, nor is the phosphorylation site in Wag $31_{\mathrm{Mtb}}$ conserved in other bacterial genera.

Our data thus suggest that the signal transduction pathway involving Wag31 and $\mathrm{PknA} / \mathrm{B}$ plays a unique role in regulating peptidoglycan synthesis at cell poles in mycobacteria. This Wag31-regulated process is essential for growth and normal rod-shaped cell morphology in mycobacteria, and thus identifies a novel target for the development of new anti-tuberculars. Further elucidation of proteins with which Wag31 interacts and the role of Wag31 phosphorylation in these interactions will provide insights into the mechanisms by which Wag31 and peptidoglycan synthesis are targeted to the cell poles. These insights will be important in understanding the regulation of mycobacterial morphology and cell division, and in understanding aspects of $M$. tuberculosis growth regulation that may play a role in the pathogenesis of tuberculosis.

\section{ACKNOWLEDGEMENTS}

We thank Dr Brian D. Robertson (Centre for Molecular Microbiology and Infection, Imperial College, London, UK) for providing the pMind plasmid. This work was supported by a fund from Wayne State University to C.-M. K. and by a grant from the US National Institutes of Health (AI 59702) to R. N.H.

\section{REFERENCES}

Av-Gay, Y. \& Everett, M. (2000). The eukaryotic-like Ser/Thr protein kinases of Mycobacterium tuberculosis. Trends Microbiol 8, 238-244.

Blokpoel, M. C., Murphy, H. N., O'Toole, R., Wiles, S., Runn, E. S., Stewart, G. R., Young, D. B. \& Robertson, B. D. (2005). Tetracyclineinducible gene regulation in mycobacteria. Nucleic Acids Res 33, e22.

Cha, J. H. \& Stewart, G. C. (1997). The divIVA minicell locus of Bacillus subtilis. J Bacteriol 179, 1671-1683.

Cole, S. T., Brosch, R., Parkhill, J., Garnier, T., Churcher, C., Harris, D., Gordon, S. V., Eiglmeier, K., Gas, S. \& other authors (1998). Deciphering the biology of Mycobacterium tuberculosis from the complete genome sequence. Nature 393, 537-544.

Daniel, R. A. \& Errington, J. (2003). Control of cell morphogenesis in bacteria: two distinct ways to make a rod-shaped cell. Cell 113, $767-776$. 
Donachie, W. D. \& Robinson, A. C. (1987). Cell division: parameter values and the process. In Escherichia coli and Salmonella typhimurium: Cellular and Molecular Biology, pp. 1578-1593. Edited by F. C. Neidhardt, J. L. Ingraham, K. B. Low, B. Magasanik, M. Schaechter \& H. E. Umbarger. Washington, DC: American Society for Microbiology.

Durocher, D., Taylor, I. A., Sarbassova, D., Haire, L. F., Westcott, S. L., Jackson, S. P., Smerdon, S. J. \& Yaffe, M. B. (2000). The molecular basis of FHA domain:phosphopeptide binding specificity and implications for phospho-dependent signaling mechanisms. Mol Cell 6, 1169-1182.

Edwards, D. H. \& Errington, J. (1997). The Bacillus subtilis DivIVA protein targets to the division septum and controls the site specificity of cell division. Mol Microbiol 24, 905-915.

Flardh, K. (2003). Essential role of DivIVA in polar growth and morphogenesis in Streptomyces coelicolor A3(2). Mol Microbiol 49, 1523-1536.

Flynn, J. L. \& Ernst, J. D. (2000). Immune responses in tuberculosis. Curr Opin Immunol 12, 432-436.

Henriques, A. O., Glaser, P., Piggot, P. J. \& Moran, C. P., Jr (1998). Control of cell shape and elongation by the rodA gene in Bacillus subtilis. Mol Microbiol 28, 235-247.

Hermans, P. W., Abebe, F., Kuteyi, V. I., Kolk, A. H., Thole, J. E. \& Harboe, M. (1995). Molecular and immunological characterization of the highly conserved antigen 84 from Mycobacterium tuberculosis and Mycobacterium leprae. Infect Immun 63, 954-960.

Hess, J., Miko, D., Catic, A., Lehmensiek, V., Russell, D. G. \& Kaufmann, S. H. (1998). Mycobacterium bovis bacille Calmette-Guerin strains secreting listeriolysin of Listeria monocytogenes. Proc Natl Acad Sci U S A 95, 5299-5304.

Kang, C. M., Abbott, D. W., Park, S. T., Dascher, C. C., Cantley, L. C. \& Husson, R. N. (2005). The Mycobacterium tuberculosis serine/ threonine kinases PknA and PknB: substrate identification and regulation of cell shape. Genes Dev 19, 1692-1704.

Lee, M. H., Pascopella, L., Jacobs, W. R., Jr \& Hatfull, G. F. (1991). Site-specific integration of mycobacteriophage L5: integrationproficient vectors for Mycobacterium smegmatis, Mycobacterium tuberculosis, and bacille Calmette-Guerin. Proc Natl Acad Sci U S A 88, 3111-3115.

Leonard, C. J., Aravind, L. \& Koonin, E. V. (1998). Novel families of putative protein kinases in bacteria and archaea: evolution of the "eukaryotic" protein kinase superfamily. Genome Res 8, 1038-1047.

Magasanik, B. (1995). Historical Perspective. In Two Component Signal Transduction, pp. 1-5. Edited by J. Hoch \& T. Silhavy. Washington, DC: American Society for Microbiology.

Marston, A. L. \& Errington, J. (1999). Selection of the midcell division site in Bacillus subtilis through MinD-dependent polar localization and activation of MinC. Mol Microbiol 33, 84-96.

Marston, A. L., Thomaides, H. B., Edwards, D. H., Sharpe, M. E. \& Errington, J. (1998). Polar localization of the MinD protein of Bacillus subtilis and its role in selection of the mid-cell division site. Genes Dev 12, 3419-3430.
Massidda, O., Anderluzzi, D., Friedli, L. \& Feger, G. (1998). Unconventional organization of the division and cell wall gene cluster of Streptococcus pneumoniae. Microbiology 144, 3069-3078.

Parish, T., Mahenthiralingam, E., Draper, P., Davis, E. O. \& Colston, M. J. (1997). Regulation of the inducible acetamidase gene of Mycobacterium smegmatis. Microbiology 143, 2267-2276.

Pashley, C. A. \& Parish, T. (2003). Efficient switching of mycobacteriophage L5-based integrating plasmids in Mycobacterium tuberculosis. FEMS Microbiol Lett 229, 211-215.

Pelicic, V., Jackson, M., Reyrat, J. M., Jacobs, W. R., Jr, Gicquel, B. \& Guilhot, C. (1997). Efficient allelic exchange and transposon mutagenesis in Mycobacterium tuberculosis. Proc Natl Acad Sci U S A 94, 10955-10960.

Pucci, M. J., Thanassi, J. A., Discotto, L. F., Kessler, R. E. \& Dougherty, T. J. (1997). Identification and characterization of cell wall-cell division gene clusters in pathogenic Gram-positive cocci. J Bacteriol 179, 5632-5635.

Raman, S., Song, T., Puyang, X., Bardarov, S., Jacobs, W. R., Jr \& Husson, R. N. (2001). The alternative sigma factor SigH regulates major components of oxidative and heat stress responses in Mycobacterium tuberculosis. J Bacteriol 183, 6119-6125.

Ramirez-Arcos, S., Liao, M., Marthaler, S., Rigden, M. \& Dillon, J. A. (2005). Enterococcus faecalis divIVA: an essential gene involved in cell division, cell growth and chromosome segregation. Microbiology 151, 1381-1393.

Ramos, A., Honrubia, M. P., Valbuena, N., Vaquera, J., Mateos, L. M. \& Gil, J. A. (2003). Involvement of DivIVA in the morphology of the rod-shaped actinomycete Brevibacterium lactofermentum. Microbiology 149, 3531-3542.

Rodriguez, M. C. \& de Pedro, M. A. (1990). Initiation of growth in pbpAts and rodAts mutants of Escherichia coli. FEMS Microbiol Lett 60, 235-239.

Sassetti, C. M., Boyd, D. H. \& Rubin, E. J. (2003). Genes required for mycobacterial growth defined by high density mutagenesis. Mol Microbiol 48, 77-84.

Thibessard, A., Fernandez, A., Gintz, B., Leblond-Bourget, N. \& Decaris, B. (2002). Effects of $\operatorname{rodA}$ and $p b p 2 b$ disruption on cell morphology and oxidative stress response of Streptococcus thermophilus CNRZ368. J Bacteriol 184, 2821-2826.

Thomaides, H. B., Freeman, M., El Karoui, M. \& Errington, J. (2001). Division site selection protein DivIVA of Bacillus subtilis has a second distinct function in chromosome segregation during sporulation. Genes Dev 15, 1662-1673.

Wayne, L. G. \& Hayes, L. G. (1996). An in vitro model for sequential study of shiftdown of Mycobacterium tuberculosis through two stages of nonreplicating persistence. Infect Immun 64, 2062-2069.

World Health Organization (2007). Tuberculosis. http://www.who.int/ mediacentre/factsheets/fs104/en/.

Yura, T., Mori, H., Nagai, H., Nagata, T., Ishihama, A., Fujita, N., Isono, K., Mizobuchi, K. \& Nakata, A. (1992). Systematic sequencing of the Escherichia coli genome: analysis of the 0-2.4 min region. Nucleic Acids Res 20, 3305-3308.

Edited by: W. Bitter 